\title{
Effects of progressive resistance training combined with a protein-enriched lean red meat diet on health-related quality of life in elderly women: secondary analysis of a 4-month cluster randomised controlled trial
}

\author{
Susan J. Torres ${ }^{1 *}$, Sian Robinson ${ }^{2,3}$, Liliana Orellana ${ }^{4}$, Stella L. O'Connell ${ }^{1}$, Carley A. Grimes ${ }^{1}$, \\ Niamh L. Mundell ${ }^{1}$, David W. Dunstan ${ }^{1,5,6}$, Caryl A. Nowson ${ }^{1}$ and Robin M. Daly ${ }^{1}$ \\ ${ }^{1}$ School of Exercise and Nutrition Sciences, Institute for Physical Activity and Nutrition, Deakin University, Geelong, \\ VIC 3220, Australia \\ ${ }^{2}$ Medical Research Council Lifecourse Epidemiology Unit, University of Southampton, Southampton SO16 6YD, UK \\ ${ }^{3}$ National Institute for Health Research (NIHR) Nutrition Biomedical Research Centre, University of Southampton and \\ University Hospital Southampton NHS Foundation Trust, Southampton SO16 6YD, UK \\ ${ }^{4}$ Biostatistics Unit, Faculty of Health, Deakin University, Geelong, VIC 3220, Australia \\ ${ }^{5}$ Baker International Diabetes Institute (IDI) Heart and Diabetes Institute, Melbourne, VIC 3004, Australia \\ ${ }^{6}$ Mary MacKillop Institute for Health Research, Australian Catholic University, Melbourne, VIC 3000, Australia
}

(Submitted 8 December 2016 - Final revision received 6 May 2017 - Accepted 13 May 2017)

\section{Abstract}

Resistance training (RT) and increased dietary protein are recommended to attenuate age-related muscle loss in the elderly. This study examined the effect of a lean red meat protein-enriched diet combined with progressive resistance training (RT + Meat) on health-related quality of life (HR-QoL) in elderly women. In this 4-month cluster randomised controlled trial, 100 women aged 60-90 years (mean 73 years) from self-care retirement villages participated in RT twice a week and were allocated either $160 \mathrm{~g} / \mathrm{d}$ (cooked) lean red meat consumed across 2 meals/d, $6 \mathrm{~d} /$ week or $\geq 1$ serving/d (25-30 g) carbohydrates (control group, CRT). HR-QoL (SF-36 Health Survey questionnaire), lower limb maximum muscle strength and lean tissue mass (LTM) (dual-energy X-ray absorptiometry) were assessed at baseline and 4 months. In all, ninety-one women (91\%) completed the study (RT + Meat ( $n$ 48); CRT ( $n$ 43)). Mean protein intake was greater in RT + Meat than CRT throughout the study (1.3 (SD 0.3) $v \cdot 1 \cdot 1$ (SD 0.3) g/kg per d, $P<0.05$ ). Exercise compliance (74\%) was not different between groups. After 4 months there was a significant net benefit in the RT + Meat compared with CRT group for overall HR-QoL and the physical component summary (PCS) score $(P<0.01)$, but there were no changes in either group in the mental component summary (MCS) score. Changes in lower limb muscle strength, but not LTM, were positively associated with changes in overall HR-QoL (muscle strength, $\beta: 2 \cdot 2$ (95\% CI $0 \cdot 1,4 \cdot 3$ ), $P<0.05$ ). In conclusion, a combination of RT and increased dietary protein led to greater net benefits in overall HR-QoL in elderly women compared with RT alone, which was because of greater improvements in PCS rather than MCS.

Key words: Quality of life: Resistance training: Dietary proteins: Red meat: Elderly women: Interventions

Most people strive to maintain their independence and quality of life (QoL) into old age, in the face of increasing life expectancy. QoL comprises broad concepts that affect global life satisfaction, including good health, adequate housing, employment, personal and family safety, interpersonal relationships, education and leisure pursuits ${ }^{(1)}$. QoL has been applied specifically to those life concerns that are most affected by health or illness, hence the term 'health-related quality of life' $(\mathrm{HR}-\mathrm{QoL})^{(2)}$. Sarcopenia, the age-related loss in muscle mass, strength and function, has been associated with multiple adverse clinical outcomes, including impaired mobility, increased risk of falls and fractures, physical disability, loss of independence, increased hospitalisation and all-cause mortality ${ }^{(3-7)}$. There is also evidence that a loss in muscle mass and strength is associated with major comorbidities, including osteoporosis, type 2 diabetes, obesity, the metabolic syndrome and $\mathrm{CVD}^{(8)}$. More recent studies have reported that sarcopenia and its determinants (losses of muscle mass, strength or function) are associated with reduced HR-QoL, particularly in terms of impaired physical function ${ }^{(9-11)}$. Indeed, the findings from a 3-year prospective

Abbreviations: CRT, control resistance training; HR-QoL, health-related quality of life; LTM, lean tissue mass; MCS, mental component summary; PCS, physical component summary; PRT, progressive resistance training; RT + Meat, resistance training plus lean red meat; SF-36, SF-36 Health Survey; QoL, quality of life.

*Corresponding author: Dr S. J. Torres, email susan.torres@deakin.edu.au 
study in older adults showed that declines in muscle mass and physical performance were associated with a deterioration in the physical QoL domain ${ }^{(12)}$. Therefore, it is likely that strategies which improve muscle strength and function may improve overall HR-QoL for older people.

Current international consensus guidelines recommend progressive resistance training (PRT) in combination with an adequate intake of dietary protein (or protein (amino acid) supplementation) as a strategy to optimise muscle mass, strength and function in older adults ${ }^{(13-16)}$. However, there have been few studies which have examined the combined effects of PRT and dietary protein on HR-QoL in communitydwelling older adults. The SF-36 Health Survey (SF-36) is a valid and reliable tool for measuring HR-QoL and health perceptions of many populations including the elderly ${ }^{(17)}$. This multi-item scale, which is designed for self-administration, contains thirtysix questions that forms eight specific health concepts (physical functioning; role limitations because of physical health; bodily pain; social functioning; general mental health; role limitations because of emotional problems; vitality and general health perceptions) as well as two aggregate summary scores: the physical component summary (PCS) and the mental component summary $(\mathrm{MCS})^{(18)}$. Several intervention trials have reported that PRT and multi-component exercise programmes can improve various measures of HR-QoL in older adults ${ }^{(19-22)}$, with some evidence that exercise-induced changes in muscle function are directly associated with improvements in HR-QoL ${ }^{(21)}$. Although less is known about the influence of dietary protein on HR-QoL in older adults, there is some evidence to support a beneficial effect ${ }^{(23,24)}$. In an 8 -week randomised controlled trial in institutionalised elderly men and women who were not at nutritional risk (mean mini nutritional assessment score $>17$ ), it was reported that supplementation with $4 \mathrm{~g}$ of essential amino acids twice a day was associated with a greater improvement in both the SF-36 MCS and PCS scores compared with placebo ${ }^{(23)}$. However, there are discordant findings from two trials which have evaluated the effects of PRT combined with protein supplementation on HR-QoL in older adults ${ }^{(25,26)}$. In a 24 -week randomised controlled trial, Tieland et at ${ }^{(25)}$ failed to observe any benefits on either PCS or MCS (SF-12) following twice weekly PRT with and without supplemental protein $(2 \times 15 \mathrm{~g}$ daily) in elderly people. In contrast, the finding from a 12 -week randomised, double-blind, placebo-controlled trial in 130 sacropenic older adults revealed that a moderate intensity multi-modal exercise programme combined with an amino acid/whey-protein $(22 \mathrm{~g} / \mathrm{d})$ and vitamin D $(2.5 \mu \mathrm{g} / \mathrm{d})$ enriched supplement led to a greater benefit in PCS scores compared with exercise alone; both groups experienced a similar significant increase in MCS scores ${ }^{(26)}$. Whether PRT combined with an increase in daily protein intake from dietary sources such as lean red meat can improve HR-QoL remains uncertain.

The aim of this study was to assess the effects of PRT combined with a protein-enriched diet achieved through the consumption of lean red meat $v$. PRT alone on overall HR-QoL, MCS, PCS and their sub-domains in communitydwelling elderly women. This study is a secondary analysis from a 4-month cluster randomised controlled trial in which we have previously reported that a lean red meat protein-enriched diet (twice daily consumption that increased protein intake to $1.3 \mathrm{~g}$ /body weight $\mathrm{kg}$ per day) combined with PRT, increased lean tissue mass (LTM) and lower limb muscle strength, and decreased markers of inflammation compared with PRT alone, in healthy elderly women ${ }^{(27)}$. Therefore, a secondary aim was to examine whether these changes in lower limb muscle strength and LTM were associated with changes in HR-QoL or their physical and mental domains.

\section{Methods}

\section{Study design}

A detailed description of the study protocol and the primary results have been reported previously ${ }^{(27)}$. In brief, this was a 4-month cluster randomised controlled trial in which fifteen retirement villages were randomly allocated to one of two groups: PRT combined with a protein-enriched diet achieved through the consumption of lean red meat twice a day (RT+Meat) or PRT combined with a control moderatecarbohydrate diet (CRT). Randomisation was conducted by an independent statistician with the use of a computer-generated randomisation of study numbers. Clusters (e.g. village) were used to minimise the potential contamination across the two diet groups and enhance feasibility.

\section{Participants}

Women recruited to the study were at least 60 years of age and residing independently in self-care retirement villages within metropolitan Melbourne, Australia. Exclusion criteria included: participation in resistance exercise ( $>1$ week) and/or moderate intensity physical activity ( $>150 \mathrm{~min} /$ week) over the past 3 months, acute or terminal illness, unstable metabolic or CVD, inflammatory bowel disease, a history of low-trauma fracture in the past 12 months, type 1 diabetes, renal impairment (estimated glomerular filtration rate $<45 \mathrm{ml} / \mathrm{min}$ ), BMI $>40 \mathrm{~kg} / \mathrm{m}^{2}$, the use of medication that might have affected muscle metabolism (corticosteroids or thyroxine), substantial weight loss $(>5 \mathrm{~kg})$ in the past 6 months, any condition that might have limited participation in the trial, or an inability to commit to the programme. Participants were not excluded on the basis of their mental health status. The study was conducted according to the guidelines laid down in the Declaration of Helsinki. All subjects provided written informed consent before commencing the study, which was approved by the Deakin University Human Ethics Committee, and registered with Australian and New Zealand Clinical Trials Registry (http://www.anzctr.org.au/, ID no. ACTRN12609000223235).

\section{Exercise intervention}

Specific details of the exercise intervention have been described previously ${ }^{(27)}$. In brief, all participants were prescribed an individually tailored and supervised progressive resistance and balance-agility training programme that was performed twice a week for 4 months. In brief, each session lasted approximately 45-60 min and consisted of the following activities: (1) 5-10 min warm-up that involved rhythmic exercises such as marching, side 
stepping and line dancing; (2) 30-40 min of low-impact balance-agility exercises and moderate intensity PRT (three sets of eight to twelve repetitions for eight different upper and lower body exercises (e.g. squats, lunges, box step-ups, leg extensions, standing leg curls, calf raises, shoulder press, upright row, bicep curls, wall push-ups and triceps kickback) using free weights (dumbbells and ankle weights) and a Swiss ball at an intensity that corresponded to 14-16 (somewhat hard to hard) on the Borg Rating of Perceived Exertion Scale and (3) a 5-10 min cool-down period that consisted of a series of stretching exercises. To deliver the exercise programme, qualified exercise trainers, with a minimum Certificate IV in Fitness qualification, drove a custom-built 'Weights on Wheels' mobile van containing the resistance training equipment to the fifteen respective retirement villages twice a week for 4 months (thirtytwo sessions per person in total). Where possible, exercise sessions were conducted before lunch or dinner so that the participants could consume their red meat meal as soon as possible following the training. Participants in the CRT group also completed their exercise sessions before lunch and dinner. Exercise compliance was computed from daily exercise cards completed by the women and checked by the trainers after each session.

\section{Dietary intervention}

Women randomised to the protein-enriched group were supplied with approximately $220 \mathrm{~g}$ (raw weight) of lean red meat for $6 \mathrm{~d}$ /week for 4 months. This amount is equivalent to two $80 \mathrm{~g}$ servings of cooked lean red meat per day (approximately $45 \mathrm{~g}$ protein; $1.3 \mathrm{~g} / \mathrm{kg}$ per $\mathrm{d}$ for an average woman weighing $78 \mathrm{~kg}$ ), and participants were asked to consume the meat at lunch and dinner each day. Participants could select from a variety of lean cuts of beef, lamb or veal that was delivered frozen (labelled in $110 \mathrm{~g}$ portion packs) every 2-4 weeks. Participants received individual counselling sessions with a dietitian, recipes and written instruction. A compliance calendar recording daily meat consumption was completed by the participants and collected every month.

Women randomised to the control group were required to consume $\geq 1$ serving of carbohydrates (approximately $1 / 2$ cup or $250 \mathrm{ml}$ ) of cooked rice or pasta or potato daily (approximately $25-35 \mathrm{~g}$ of carbohydrates) included within their usual dietary pattern. This control diet was not designed as an isoenergetic diet, and the rice/pasta was provided to assist in keeping their dietary protein intakes towards the lower range of usual intake and to ensure that both groups received the same level of attention. Participants were provided with packs of pasta and rice every 2-4 weeks and were encouraged to focus on having larger servings of breads, cereals and vegetables and smaller servings of protein foods. As with the protein-enriched group, participants received counselling, recipes and instructions. A record of carbohydrate-rich meals to measure dietary compliance was completed daily.

All participants were required to take one $25 \mu \mathrm{g}$ vitamin $\mathrm{D}_{3}$ capsule per day. These capsules were provided at the beginning of the study and compliance was checked by counting the capsules returned at the end of 4 months.

\section{Health-related quality of life}

HR-QoL was assessed using the SF-36 version 1 questionnaire at baseline and 4 months ${ }^{(18)}$. This multi-item scale, which is designed for self-administration, contains thirty-six questions from which two summary scores are derived: the PCS and the MCS. In addition, scores were calculated for each of eight health sub-domains: physical QoL included physical functioning (physical health), role physical (role limitation because of physical health), bodily pain, general health (general health perceptions); and mental QoL included vitality, social functioning, role emotional (role limitations because of emotional problems) and mental health (general mental health). An overall HR-QoL score was calculated as the mean of all the eight health sub-domains. Higher scores indicate better quality of life. All scores are reported using Australian normbased scores according to previously published guidelines ${ }^{(28,29)}$. The use of norm-based weights gives each domain score a mean of 50 and a SD of 10, allowing change in scores to be assessed on a comparable scale. The SF-36 has demonstrated good construct validity, internal consistency and test-retest reliability ${ }^{(17,30,31)}$.

\section{Anthropometric measures}

Height was measured to the nearest $\mathrm{mm}$ using a stadiometer (Holtain Ltd) and weight to the nearest $0 \cdot 1 \mathrm{~kg}$ was assessed using a digital scale (BWB 800; Wedderburn Australia). BMI was calculated as weight $(\mathrm{kg})$ divided by height $\left(\mathrm{m}^{2}\right)$.

\section{Muscle strength and lean tissue mass}

As reported in detail previously ${ }^{(27)}$, lower limb muscle strength (one-repetition maximum (RM) estimated from a 3-RM test) was assessed on a leg-extension machine (FreeMotion Fitness). Leg LTM was assessed from a total body scan by using dual-energy X-ray absorptiometry (Lunar Prodigy; GE Lunar Corp.) with software version 12.30.008.

\section{Diet and physical activity assessment}

As reported previously ${ }^{(27)}$, nutrient intake was assessed at baseline and every 4 weeks throughout the study by using telephone-facilitated 24-h dietary recalls performed by trained research dietitians. Daily energy, macronutrient and micronutrient intake was determined using Foodworks Professional Edition (version 6.0.2562; Xyris Software), which was linked to the 2007 AUSNUT food composition database. The amount of total leisure and recreational physical activity time was assessed at baseline and 4 months using the Community Healthy Activities Model Program for Seniors questionnaire developed and validated for use with older adults ${ }^{(32)}$.

\section{Health and lifestyle measures}

Demographic and lifestyle variables (age, education, smoking, chronic health conditions) and history of hormone replacement therapy (HRT) use were collected using self-administered questionnaires at baseline ${ }^{(27)}$. Educational status was categorised as: never attended school, completed primary school, some 
high school, completed high school, technical/trade certificate or university/tertiary level. Participants were categorised as never smokers, ex-smokers and current smokers. History of chronic disease was categorised as: none, 1 or $\geq 2$ chronic health conditions.

\section{Statistical analysis and sample size}

Statistical analysis was performed using SPSS 22.0 for Windows (SPSS Inc.) and SAS 9.3 (SAS Institute). Because of nonnormality, leg muscle strength and LTM were log transformed before analysis. Baseline characteristics in the RT + Meat and CRT groups were compared using $\chi^{2}$ test for categorical variables (education, smoking, HRT use and chronic health condition) and linear models accounting for clustering for the continuous variables (age, age at menopause, BMI, physical activity, leg muscle strength and leg LTM). The effect of the intervention on HR-QOL and diet was assessed using linear mixed models including group, time (HR-QoL: baseline and 4 months; diet: baseline, 1, 2, 3 and 4 month time points) and the group $\times$ time interaction as fixed effects, with village as a random effect to account for the cluster randomisation. In a second model we also adjusted for the change in habitual physical activity. Unstructured covariance matrix was assumed for the repeated measures. In all, eleven HR-QoL-related outcome variables were considered: physical functioning, role physical, bodily pain, general health, vitality, social functioning, role emotional, mental health, PCS, MCS and the overall HRQoL score. All data were analysed by using an intention-to-treat approach. Results are presented as model estimates and 95\% CI. Robust linear regression models (M-estimates) including group, change in log muscle strength or leg LTM, and the interaction term were used to explore the association between changes in strength or leg LTM (independent variable) with changes in overall HR-QOL, PCS and MCS (outcome variables). As the interaction term was not significant in any of the models, all results are based on models including only group and change in log lower limb muscle strength and leg LTM. $P<0.05$ was considered statistically significant.

\section{Sample size}

The trial was designed to have adequate power to detect a difference in the change in total body LTM between the groups $^{(27)}$. Given strong recommendations against their use ${ }^{(33)}$, post hoc power calculations were not performed for this secondary analysis of HR-QoL scores.

\section{Results}

\section{Participant characteristics}

In all, 100 women were found to be eligible and randomised to one of the two groups (RT+Meat: $n$ 53; CRT: $n$ 47) (Fig. 1). Nine participants withdrew from the study over the 4-month period (RT+Meat: $n$ 5; CRT: $n$ 4). Reasons for withdrawal included medical issues unrelated to the study ( $n 5$ ), work or personal time commitments ( $n$ 2), and personal reasons ( $n$ 2) unrelated to the study ${ }^{(27)}$. There was no significant difference in age, weight and BMI between those who completed and those who withdrew from the study. A total of forty-eight women in the RT + Meat and forty-three women in the CRT group completed the study. A total of thirty-one (32\%) women were smokers or ex-smokers; thirty (31\%) had no health condition(s) and thirty-eight (37\%) had not completed high school (Table 1). The study recruitment and intervention were conducted in two cohorts over 2 years from January 2009 to December 2010.

\section{Diet, exercise adherence and habitual physical activity}

For each individual, the number of meat or carbohydrate portions consumed during the study as a proportion of the total number prescribed (i.e. 2 servings meat/d for $6 \mathrm{~d} /$ week, or at least 1 serving carbohydrate/d per week) was calculated and expressed as a percentage. As reported previously ${ }^{(27)}$, the average adherence was $81 \%$ in the RT + Meat and $100 \%$ in the CRT group. Estimated dietary intakes were similar between the groups at baseline, with the exception the percentage energy from carbohydrate was greater in the RT + Meat compared with the CRT group (Table 1). Mean dietary protein intake $(\mathrm{g} / \mathrm{d})$ was significantly greater in the RT + Meat compared with CRT group at months 2, 3 and 4 (Fig. 2). Baseline mean daily protein intake expressed as $\mathrm{g} / \mathrm{kg}$ body weight was 1.07 $(\mathrm{sD} 0.37) \mathrm{g} / \mathrm{kg} / \mathrm{d}$ in the RT + Meat group and $1.13(\mathrm{SD} 0 \cdot 40) \mathrm{g} / \mathrm{kg}$ per $\mathrm{d}$ in the CRT group. Throughout the intervention, the average protein intake (mean of months 1-4) was significantly greater in the RT + Meat compared with CRT group (mean 1.29 (SD 0.30) v. $1 \cdot 15$ (SD 0.35) $\mathrm{g} / \mathrm{kg}$ per $\mathrm{d}, P<0.05)$. For both groups combined at baseline, $85 \%$ of women aged $51-70$ years and $56 \%$ aged greater than 70 years exceeded the current Australian recommended dietary intake of protein of 0.75 and $0.94 / \mathrm{g} / \mathrm{kg}$ per $\mathrm{d}$, respectively ${ }^{(34)}$. Mean adherence to the exercise classes for all women was $74 \%$, and did not differ between the RT+ Meat $(75 \%$; $95 \%$ CI 68, 82) and CRT (72\%; $95 \%$ CI 64, 80) group. In the CRT group, habitual physical activity increased compared with the RT + Meat group throughout the study [mean change at 4 months: $2 \cdot 8$ (SD 5.1) v. -0.3 (sD 4.7) h/week, $P<0 \cdot 01)$.

\section{Effects of the intervention on health-related quality of life}

There were no significant differences between the two groups in any of the HR-QoL domains at baseline (Table 2, all $P>0 \cdot 10$ ). Comparison of the changes over time between the groups revealed that there was a significant net benefit (group $\times$ time interaction) to the RT + Meat compared with CRT group for the following measures (Table 2): overall HR-QoL $(P=0 \cdot 009)$, PCS $(P=0.007)$, and the sub-domains: physical functioning $(P=0.043)$, role physical $(P=0.041)$ and bodily pain $(P=0.021)$. For overall HR-QoL, this was driven by a significant increase in the RT+Meat group $(P=0.047)$ with a nonsignificant reduction in the CRT group $(P=0.075)$. For PCS, the net difference was because of a non-significant increase in the RT + Meat group $(P=0 \cdot 260)$ and a significant decrease in the CRT group $(P=0 \cdot 007)$. For both physical functioning and role physical, the net benefit to the $\mathrm{RT}+$ Meat group was because of a non-significant increase $(P=0.074$ and $P=0.235$, 


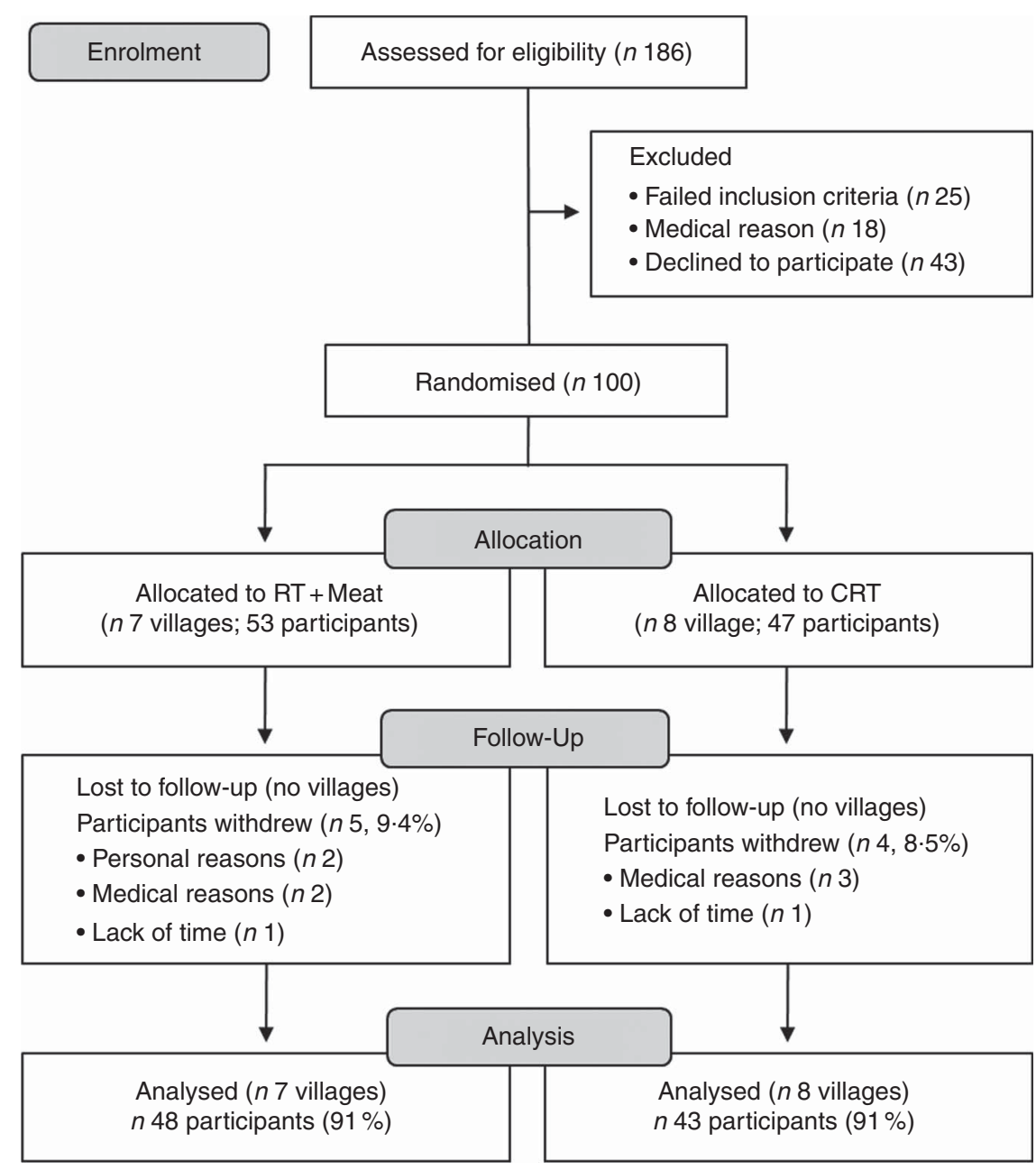

Fig. 1. Flowchart of participants through the study. RT + Meat, resistance training plus lean red meat; CRT, control resistance training group.

respectively) in this group and a non-significant decrease in the CRT group ( $P=0.268$ and $P=0.089$, respectively). For bodily pain, the net benefit was related to a non-significant decrease in the RT + Meat group $(P=0.901)$ and a significant decrease in the CRT group $(P=0 \cdot 001)$. All results remained unchanged after adjusting for the change in habitual physical activity. There were no significant between-group differences for the change in MCS or its sub-domains after 4 months.

\section{Regression results for muscle mass, muscle strength and} health-related quality of life

An exploratory analysis of the association between changes in HR-QoL scores and changes in leg LTM and lower limb muscle strength, after adjusting for group, showed that the change in the overall HR-QoL was positively associated with the change in log muscle strength but not log leg LTM (muscle strength $\beta: 2 \cdot 2$; 95\% CI 0.1, 4.3, $P=0 \cdot 037$; leg LTM $\beta$ : 18.9; $95 \%$ CI $-10 \cdot 3$, 48.1, $P=0.205)$. The change in the mental health sub domain showed the same pattern of association ( $\log$ muscle strength $\beta$ : 4.3; $95 \%$ CI $1 \cdot 1,7 \cdot 5, P=0 \cdot 008$; log muscle mass $\beta$ : $24 \cdot 0 ; 95 \% \mathrm{CI}$ $-19 \cdot 2,67 \cdot 2, P=0 \cdot 280)$. There was no association between changes in muscle strength or LTM with changes in PCS scores (muscle strength $\beta$ : 0.4; 95\% CI $-2 \cdot 6,3 \cdot 5, P=0 \cdot 79$; LTM $\beta: 22 \cdot 3$; $95 \%$ CI $-22 \cdot 9,67 \cdot 4, P=0 \cdot 33)$.

\section{Discussion}

The findings from this secondary analysis of a 4-month cluster randomised controlled trial indicate that combining PRT with a diet enriched with lean red meat to increase dietary protein intake, compared with PRT alone, was associated with a modest (7\%) but significantly greater improvement in overall HR-QoL, which was largely associated with the physical rather than mental health domains. Additional exploratory analysis also revealed that PRT combined with lean red meat induced changes in lower limb muscle strength, but not leg LTM, were associated with changes in both overall HR-QoL and the mental health sub domain scores. This finding adds to the growing body of evidence supporting the various health and psychological benefits associated with preserving muscle strength into old age.

The finding that the provision of additional protein enhanced the effects of PRT on overall HR-QoL and PCS scores is 
Table 1. Baseline characteristics of the participants in the resistance training (RT) plus lean red meat group (RT + Meat) and the control RT group (CRT)

(Mean values and standard deviations; numbers and percentages)

\begin{tabular}{|c|c|c|c|c|c|}
\hline \multirow[b]{2}{*}{ Variables } & \multicolumn{2}{|c|}{$\mathrm{RT}+$ Meat $(n 53)$} & \multicolumn{2}{|c|}{ CRT ( $n$ 47) } & \multirow[b]{2}{*}{$P$} \\
\hline & Mean & SD & Mean & SD & \\
\hline Age (years) & $72 \cdot 1$ & $6 \cdot 4$ & $73 \cdot 6$ & $7 \cdot 7$ & 0.417 \\
\hline Weight (kg) & $70 \cdot 0$ & 11.3 & 68.4 & 11.5 & 0.384 \\
\hline BMI $\left(\mathrm{kg} / \mathrm{m}^{2}\right)$ & $27 \cdot 7$ & 3.9 & $27 \cdot 6$ & 4.9 & 0.871 \\
\hline Age at menopause (years) & $49 \cdot 3$ & $6 \cdot 6$ & $47 \cdot 7$ & $5 \cdot 3$ & 0.169 \\
\hline Use of HRT* ${ }^{*}$ & & & & & 0.986 \\
\hline$n$ & & & & & \\
\hline$\%$ & & & & & \\
\hline Physical activity (h/week) & $9 \cdot 3$ & $5 \cdot 6$ & $8 \cdot 1$ & $4 \cdot 0$ & 0.330 \\
\hline \multirow{2}{*}{\multicolumn{6}{|c|}{$\begin{array}{l}\text { Education† } \\
\text { Did not complete high school }\end{array}$}} \\
\hline & & & & & \\
\hline$n$ & \multicolumn{2}{|c|}{20} & \multicolumn{2}{|c|}{16} & \\
\hline$\%$ & \multicolumn{2}{|c|}{$37 \cdot 7$} & \multicolumn{2}{|c|}{$35 \cdot 6$} & \\
\hline \multicolumn{6}{|l|}{ Completed high school } \\
\hline$n$ & \multicolumn{2}{|c|}{14} & \multicolumn{2}{|c|}{7} & \\
\hline$\%$ & \multicolumn{2}{|c|}{$26 \cdot 4$} & \multicolumn{2}{|c|}{$15 \cdot 6$} & \\
\hline \multicolumn{6}{|l|}{ Technical/trade certificate } \\
\hline$n$ & \multicolumn{2}{|c|}{8} & \multicolumn{2}{|c|}{6} & \\
\hline$\%$ & \multicolumn{2}{|c|}{$15 \cdot 1$} & \multicolumn{2}{|c|}{$13 \cdot 3$} & \\
\hline \multicolumn{6}{|l|}{ University or Tertiary level } \\
\hline$n$ & \multirow{2}{*}{\multicolumn{2}{|c|}{$\begin{array}{c}11 \\
20 \cdot 8\end{array}$}} & & & \\
\hline$\%$ & & & & & \\
\hline Smoking status & & & & & 0.919 \\
\hline Current or ex-smoker & & & & & \\
\hline$n$ & & & & & \\
\hline$\%$ & & & & & \\
\hline Non-smoker & & & & & \\
\hline$n$ & & & & & \\
\hline$\%$ & & & & & \\
\hline Chronic health condition & & & & & 0.162 \\
\hline No health conditions & & & & & \\
\hline$n$ & & & & & \\
\hline$\%$ & & & & & \\
\hline 1 health condition & & & & & \\
\hline$n$ & & & & & \\
\hline$\%$ & & & & & \\
\hline$\geq 2$ health conditions & & & & & \\
\hline$n$ & & & & & \\
\hline$\%$ & & & & & \\
\hline Dietary intakes & & & & & \\
\hline Energy intake $(\mathrm{kJ} / \mathrm{d})$ & 6160 & 1513 & 6612 & 1593 & 0.088 \\
\hline Protein $(\mathrm{g} / \mathrm{d})$ & 73 & 23 & 76 & 27 & 0.570 \\
\hline Protein (\% of energy) & $19 \cdot 7$ & 4.4 & 18.9 & $5 \cdot 0$ & 0.335 \\
\hline Protein $(\mathrm{g} / \mathrm{kg}$ per $\mathrm{d})$ & 1.07 & 0.37 & $1 \cdot 13$ & 0.40 & 0.483 \\
\hline Carbohydrates $(\mathrm{g} / \mathrm{d})$ & 171 & 48 & 172 & 57 & 0.897 \\
\hline Carbohydrates ( $\%$ of energy) & $44 \cdot 3$ & 7.6 & $40 \cdot 7$ & 7.9 & 0.041 \\
\hline Fat $(g / d)$ & 53 & 22 & 61 & $19 \cdot 2$ & 0.072 \\
\hline Fat (\% of energy) & $30 \cdot 0$ & 8.4 & 33.4 & $8 \cdot 1$ & 0.124 \\
\hline Leg muscle strength (kg) & $32 \cdot 0$ & $11 \cdot 2$ & $28 \cdot 1$ & $10 \cdot 1$ & 0.177 \\
\hline Total leg lean tissue mass $(\mathrm{kg})$ & $11 \cdot 8$ & 1.7 & 11.9 & 1.4 & 0.879 \\
\hline
\end{tabular}

HRT, hormone replacement therapy.

* Missing data for three subjects in the CRT group.

$\dagger$ Missing data for two subjects in the CRT group.

consistent with the results from a 12-week intervention in which a moderate intensity multi-modal exercise programme combined with an amino acid/whey-protein $(22 \mathrm{~g} / \mathrm{d})$ and vitamin D $(2.5 \mu \mathrm{g} / \mathrm{d})$ enriched supplement led to a net $6 \%$ improvement in PCS scores compared with exercise alone in sixty-nine elderly (mean age 80 years) sarcopenic people; in this study, both groups experienced a similar significant increase in MCS scores $^{(26)}$. Similarly, the findings from a short-term prospective study in ninety-one institutionalised frail elderly people showed that HR-QoL (assessed via the EuroQol-5 Dimensions questionnaire) improved after 6 and 12 weeks with a nutritional supplement and exercise programme ${ }^{(35)}$. In this study, participants were asked to take two daily oral nutritional supplements each containing $20 \mathrm{~g}$ of protein, $12.5 \mu \mathrm{g}$ of vitamin $\mathrm{D}, 480 \mathrm{mg}$ of $\mathrm{Ca}$ and $3 \mathrm{~g}$ of fibre plus and undertake a multi-modal exercise programme performed $5 \mathrm{~d} /$ week $^{(35)}$. Although a limitation of this study is that there was no exercise alone or control group, making it difficult to determine whether it was the exercise or nutritional supplement 

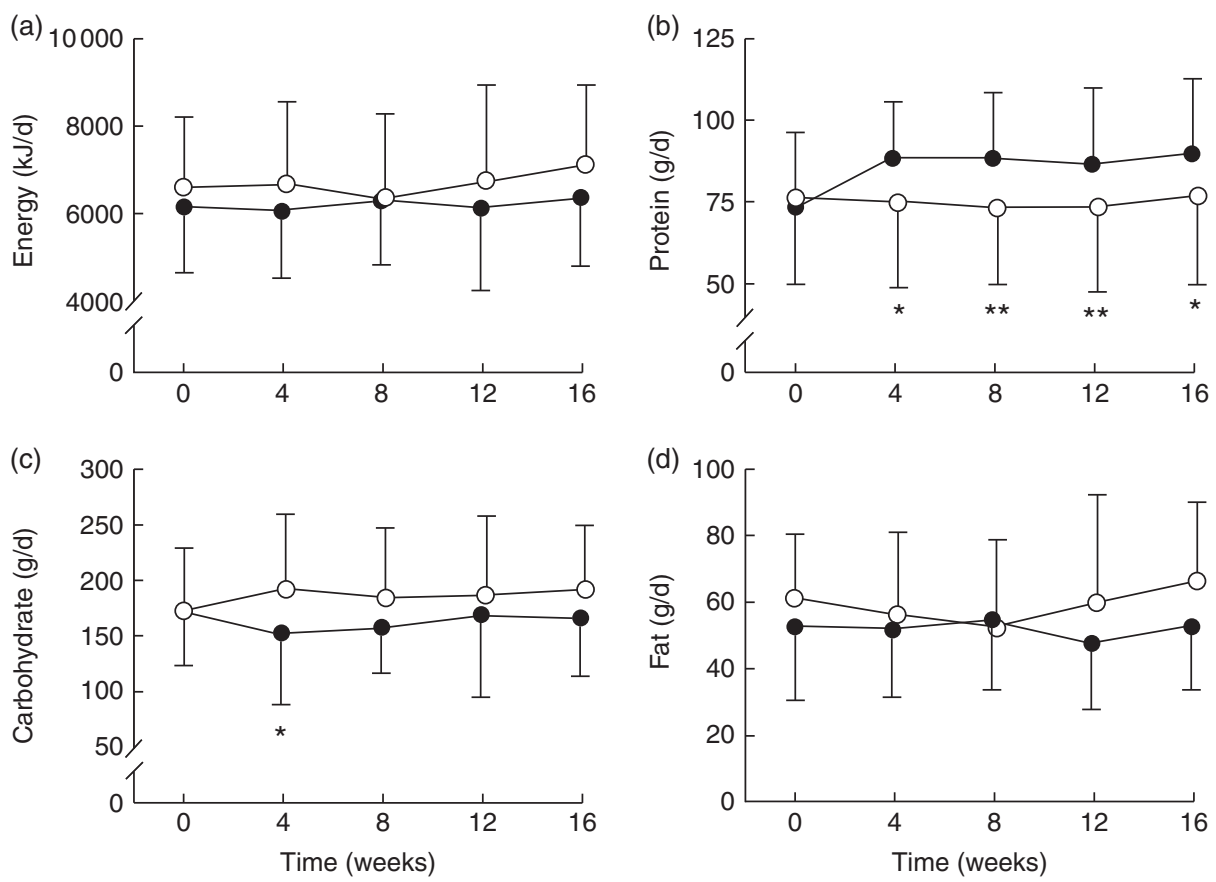

Fig. 2. Estimated (a) energy, (b) protein, (c) carbohydrate and (d) fat during the 4-month intervention for the resistance training plus lean red meat group (O) and carbohydrate control group $(O)$. Values are means and standard deviations. Net between-group differences for the change over time: ${ }^{*} P<0.05,{ }^{\star *} P<0.01$.

Table 2. Mean baseline values and the within group changes in the resistance training (RT) plus lean red meat group (RT + Meat) ( $n$ 53) and the control RT (CRT) ( $n$ 47) group for quality of life measures and the net between-group differences for the change relative to baseline*

(Mean values with their standard errors; mean values and 95\% confidence intervals)

\begin{tabular}{|c|c|c|c|c|c|c|c|c|}
\hline \multirow[b]{2}{*}{ SF-36 scores } & \multirow[b]{2}{*}{ Group } & \multicolumn{2}{|c|}{ Baseline scores } & \multicolumn{2}{|c|}{ Change from baseline } & \multicolumn{2}{|c|}{ Net difference for change } & \multirow[b]{2}{*}{ Group $\times$ time interaction $(P)$} \\
\hline & & Mean & $\mathrm{SE}$ & Mean & $95 \% \mathrm{Cl}$ & Mean & $95 \% \mathrm{Cl}$ & \\
\hline \multirow[t]{2}{*}{ HR-QoL } & $\mathrm{RT}+$ Meat & $51 \cdot 2$ & 0.9 & $1 \cdot 3$ & $0.02,2.5$ & $2 \cdot 5$ & $0.6,4 \cdot 3$ & 0.009 \\
\hline & CRT & 51.0 & 1.0 & $-1 \cdot 2$ & $-2 \cdot 5,0 \cdot 1$ & & & \\
\hline \multirow[t]{2}{*}{ PCS } & RT + Meat & $47 \cdot 8$ & $1 \cdot 3$ & $1 \cdot 1$ & $-0.8,3.0$ & 3.9 & $1 \cdot 1,6 \cdot 6$ & 0.007 \\
\hline & CRT & $49 \cdot 8$ & 1.4 & $-2 \cdot 8$ & $-4.8,-0.8$ & & & \\
\hline \multirow[t]{2}{*}{ Physical functioning } & RT + Meat & $47 \cdot 2$ & $1 \cdot 3$ & 1.4 & $-0.1,3 \cdot 0$ & $2 \cdot 3$ & $0 \cdot 1,4 \cdot 6$ & 0.043 \\
\hline & CRT & $47 \cdot 3$ & 1.4 & -0.9 & $-2 \cdot 6,0 \cdot 7$ & & & \\
\hline \multirow[t]{2}{*}{ Role physical } & RT + Meat & $49 \cdot 4$ & 1.7 & $1 \cdot 8$ & $-1 \cdot 2,4 \cdot 8$ & 4.5 & $0.2,8.9$ & 0.041 \\
\hline & CRT & $50 \cdot 2$ & $1 \cdot 8$ & $-2 \cdot 7$ & $-5 \cdot 9,0.4$ & & & \\
\hline \multirow[t]{2}{*}{ Bodily pain } & RT + Meat & 48.8 & 1.2 & -0.1 & $-2 \cdot 1,1 \cdot 9$ & 3.4 & $0.5,6.3$ & 0.021 \\
\hline & CRT & $50 \cdot 8$ & $1 \cdot 3$ & -3.5 & $-5 \cdot 6,-1 \cdot 4$ & & & \\
\hline \multirow{2}{*}{ General health } & RT + Meat & $52 \cdot 1$ & $1 \cdot 2$ & $1 \cdot 1$ & $-0.8,3.0$ & $2 \cdot 6$ & $-0 \cdot 2,5 \cdot 3$ & 0.069 \\
\hline & CRT & $52 \cdot 6$ & 1.3 & -1.5 & $-3.5,0.5$ & & & \\
\hline \multirow[t]{2}{*}{ MCS } & $\mathrm{RT}+$ Meat & $55 \cdot 0$ & $1 \cdot 1$ & 1.4 & $-0.5,3 \cdot 3$ & 0.7 & $-2 \cdot 0,3 \cdot 4$ & 0.621 \\
\hline & CRT & $52 \cdot 3$ & 1.2 & 0.7 & $-1 \cdot 2,2 \cdot 7$ & & & \\
\hline \multirow[t]{2}{*}{ Vitality } & RT + Meat & $53 \cdot 3$ & $1 \cdot 3$ & 1.5 & $-0.3,3 \cdot 3$ & 0.6 & $-2 \cdot 0,3 \cdot 2$ & 0.653 \\
\hline & CRT & 51.6 & 1.4 & 0.9 & $-1 \cdot 0,2 \cdot 9$ & & & \\
\hline \multirow[t]{2}{*}{ Social functioning } & RT + Meat & $52 \cdot 9$ & 1.2 & 0.9 & $-2 \cdot 0,3 \cdot 7$ & 1.2 & $-2 \cdot 9,5 \cdot 3$ & 0.577 \\
\hline & CRT & $51 \cdot 1$ & $1 \cdot 3$ & -0.3 & $-3 \cdot 3,2 \cdot 7$ & & & \\
\hline \multirow[t]{2}{*}{ Role emotional } & $\mathrm{RT}+$ Meat & $51 \cdot 7$ & $1 \cdot 2$ & 1.7 & $-0.6,3.9$ & $2 \cdot 3$ & $-0.9,5 \cdot 6$ & 0.153 \\
\hline & CRT & $49 \cdot 9$ & $1 \cdot 3$ & -0.7 & $-3 \cdot 0,1 \cdot 7$ & & & \\
\hline \multirow[t]{2}{*}{ Mental health } & RT + Meat & $54 \cdot 6$ & $1 \cdot 2$ & 1.5 & $-0.5,3.4$ & 0.9 & $-1 \cdot 9,3 \cdot 6$ & 0.547 \\
\hline & CRT & $52 \cdot 4$ & $1 \cdot 3$ & 0.6 & $-1 \cdot 4,2 \cdot 6$ & & & \\
\hline
\end{tabular}

SF-36, SF-36 Health Survey; HR-QoL, health-related quality of life; PCS, physical component summary; MCS, mental component summary.

* $P$ values based on linear mixed models with group, time and group $\times$ time as fixed effects and village as random effect (unstructured covariance matrix for repeated measures).

that contributed to the improvement in HR-QoL, collectively these findings provide some evidence that nutritional supplementation with additional protein (and other nutrients) may enhance the effects of exercise on HR-QoL in older adults and the elderly, particularly the physical health domains.
The observation that there was a greater net benefit in PCS scores in the RT + Meat group compared with the CRT group is consistent with evidence from a number of intervention studies in older adults showing that protein supplementation can augment the effects of PRT on muscle mass and 
strength $^{(25,26,36)}$. As previously reported ${ }^{(27,37)}$, there is evidence that the anabolic sensitivity of skeletal muscle to dietary protein is blunted with ageing, which has been termed 'anabolic resistance'. Thus, it has been recommended that older adults require a daily protein intake $>1.2-1.5 \mathrm{~g} / \mathrm{kg}$ to maximise the anabolic response to exercise ${ }^{(14)}$. Consistent with these guidelines, we found that increasing mean dietary protein intake from 1.1 to $1.3 \mathrm{~g} / \mathrm{kg}$ per $\mathrm{d}$ was associated with a greater exerciseinduced increase in muscle mass and strength ${ }^{(27)}$. Whether there is an optimal protein intake to enhance the effects of PRT on HR-QoL remains unknown. Nevertheless, previous research in older adults has shown that physical functioning plays a key role in QoL, with the main drivers being energy, freedom from pain, ability to undertake activities of daily living and ability to move around ${ }^{(11)}$. In our study, we found that women in the $\mathrm{RT}+$ Meat group experienced significant net benefits in the subdomains of physical functioning, role physical and bodily pain compared with the CRT group. It is also noteworthy that changes in lower limb muscle strength (but not LTM) in the women in our study were positively associated with changes in overall HR-QoL, which suggests that improving muscle strength may be a key element to improving HR-QoL during ageing.

Another interesting finding from our study was that there were no significant changes in MCS scores (or its sub-domains) in either group after 4 months of training. A likely explanation for this result is that we only included relatively healthy older women who were residing independently in self-care retirement villages, and excluded those with any serious chronic disease(s) or conditions that would limit participation in the exercise programme. In partial support of this notion, a previous 10-week intervention in untrained adults aged 40-69 years showed that PRT only improved physical (physical functioning, general health) and mental health (social functioning) dimensions of QoL in those who had a high, but not low, number of metabolic risk factors ${ }^{(38)}$. Others have shown that HR-QoL is linked to the presence of chronic disease ${ }^{(39)}$, and thus exercise could have greater benefits in this population group. In our study, the average baseline MCS scores of the women was higher than that of a similar population sample of Australian women aged 65 years and older ${ }^{(40)}$, which suggests that there may have been limited capacity for any improvement in MCS scores over the 4-month intervention.

A number of previous PRT interventions have observed improvements in HR-QOL in older adults and the elderly ${ }^{(20,21)}$, including physical functioning, role physical, general health, vitality and mental health ${ }^{(41)}$. However, others have reported limited or no benefits ${ }^{(19,42-44)}$. The reason(s) for these contrasting results remains unclear, but may relate to differences in the health status of participants (e.g. depressive or mental state), level of social interaction or supervision association with each intervention (e.g. group $v$. individual training) and/or differences in the training doses (e.g. frequency, intensity, duration). In our study, we found that PRT alone was not effective for improving any measure of HR-QoL, in fact, after 4 months there was a trend for overall HR-QoL to decrease relative to baseline in the CRT group. In the present study, all women trained in small groups to promote social interaction and were prescribed a supervised moderate to high intensity training programme which significantly improved muscle strength and function, and so it is unlikely these factors would explain the trend for a decrease in HR-QoL in the CRT group ${ }^{(27)}$. The frequency of training and the duration of the PRT intervention (e.g. PRT twice a week for 16 weeks) may have also played a role in the lack of an effect on HR-QoL. In part support of this notion, Sillanpää et $a l .^{(44)}$ reported that strength training twice a week for 21 weeks in healthy middle aged and older adults resulted in no changes in HR-QoL as measured by the SF-36 questionnaire.

Previous research has shown that sarcopenia and its determinants are associated with a decrease in HR-QoL, particularly the physical function domain, independent of age, physical activity and/or comorbidities ${ }^{(9,12,45,46)}$. Furthermore, several exercise intervention trials have shown that changes in lower extremity muscle strength or function were positively associated with changes in various measures of HR-QoL ${ }^{(21,22,38,47)}$. Consistent with these results, we found that exercise-protein induced changes in lower limb muscle strength in elderly women were significantly associated with changes in the overall HR-QoL and the mental health sub domain, however the change in muscle strength was not associated with the change in PCS scores. The findings from a previous 8-month intervention also revealed that exercise-induced changes in functional capacity (stair ascent performance) were associated with changes in bodily pain, mental health and MCS scores in community-dwelling older adults, but changes in PCS scores were not related to any changes in strength or function ${ }^{(48)}$. The authors suggested that increases in functional capacity may provide a global indicator of health and functioning and thereby lead to improvements in mental health and well-being. Nevertheless, these findings further reinforce the importance of maintaining (or improving) functional capacity, particularly lower limb muscle strength, in later life.

There are a number of limitations associated with this study which must be considered when interpreting the findings. First, this was a secondary analysis of a randomised controlled trial in which the primary outcome was changes in LTM and muscle strength. Thus, this study was not designed to improve HR-QoL or specifically powered to detect any potential between-group differences. Second, in the absence of a non-exercising control group, we were unable to determine whether either intervention was better than standard care. Third, the sample included relatively healthy, independent living women with no serious medical conditions, which limits the generalisability of the findings to other groups. Fourth, exercise adherence of $74 \%$. Although this may be viewed as modest, this is comparable with other similar exercise trials which reported adherence rates ranging from 79 to $87 \%(20,38,49,50)$. Furthermore, it is worth noting that both the RT + Meat and CRT group experienced significant improvements in muscle strength, leg muscle cross-sectional area and certain measures of muscle function, as reported in our previous paper ${ }^{(27)}$. This indicates that our exercise programme and a compliance of $74 \%$ was effective. Finally, the self-report recall nature of the SF-36 questionnaire is prone to reporting bias and has a ceiling effect which may limit the ability to detect subtle changes in response to an exercise-protein intervention in relatively healthy older women. Although it is possible that other QoL instruments may be more 
sensitive to changes in QoL following an exercise-nutrition intervention, net between-group differences for the change in various HR-QoL scores over 16 weeks in our study supports the use of the SF-36 questionnaire in healthy community-dwelling older adults.

In conclusion, this study has shown that a supervised and structured PRT programme conducted within self-care retirement villages in combination with a protein-enriched diet through the consumption of lean red meat led to greater net benefits in HR-QoL compared with PRT alone in healthy elderly women. Furthermore, this finding adds to the growing body of evidence to support the health and well-being benefits of increasing high quality dietary protein intake in older adults and the elderly, particularly in combination with exercise.

\section{Acknowledgements}

The authors are very grateful to the managers and volunteers of the retirement/lifestyle villages who took part in the Women's Healthy Ageing and Muscle (WHAM) study: Burwood Terrace, Salford Park, Bedford Heights Estate, Knox Village, Waterford Park Retirement Village, Yarbatt Place, Wantirna Village, Prospect Hill, Cherry Tree Grove, Balmoral Gardens, Cumberland View, Walmsley, Sackville Grange, Tudor Village and Lexington Gardens.

Professor R. M. D. was supported by a National Health and Medical Research Council (NHMRC) Career Development Award (ID 425849). Professor D. W. D. is supported by a NHMRC Senior Research Fellowship (NHMRC no. 1078360). This study was supported by a competitive peer-reviewed grant from Meat and Livestock Australia Ltd (D.MHN.0030). The sponsor had no role in the design and conduct of the study, collection, management and interpretation of the data, or preparation of the manuscript.

R. M. D., C. A. N. and D. W. D. designed the study; N. L. M., S. L. O. and C. A. G. conducted the research; C. A. G created the database; S. R. conducted preliminary analysis on the quality of life data; S. L. O. conducted the statistical analysis; S. J. T., S. L. O. and R. M. D. interpreted the results; S. J. T. and R. M. D. wrote the manuscript; and all authors critically reviewed the manuscript and read and approved the final version of the manuscript.

None of the authors has any conflicts of interest to declare

\section{References}

1. Felce D \& Perry J (1995) Quality of life: its definition and measurement. Res Dev Disabil 16, 51-74.

2. Bergner M (1989) Quality of life, health status, and clinical research. Med Care 27, S148-S156.

3. Fielding RA, Vellas B, Evans WJ, et al. (2011) Sarcopenia: an undiagnosed condition in older adults. Current consensus definition: prevalence, etiology, and consequences. International working group on sarcopenia. J Am Med Dir Assoc 12, 249-256.

4. Janssen I, Baumgartner RN, Ross R, et al. (2004) Skeletal muscle cutpoints associated with elevated physical disability risk in older men and women. Am J Epidemiol 159, 413-421.

5. Landi F, Liperoti R, Russo A, et al. (2012) Sarcopenia as a risk factor for falls in elderly individuals: results from the ilSIRENTE study. Clin Nutr 31, 652-658.
6. Landi F, Cruz-Jentoft AJ, Liperoti R, et al. (2013) Sarcopenia and mortality risk in frail older persons aged 80 years and older: results from ilSIRENTE study. Age Ageing 42, 203-209.

7. Landi F, Liperoti R, Fusco D, et al. (2012) Sarcopenia and mortality among older nursing home residents. J Am Med Dir Assoc 13, 121-126.

8. Kalyani RR, Corriere M \& Ferrucci L (2014) Age-related and disease-related muscle loss: the effect of diabetes, obesity, and other diseases. Lancet Diabetes Endocrinol 2, 819-829.

9. Sayer AA, Syddall HE, Martin HJ, et al. (2006) Is grip strength associated with health-related quality of life? Findings from the Hertfordshire Cohort Study. Age Ageing 35, 409-415.

10. Iannuzzi-Sucich M, Prestwood KM \& Kenny AM (2002) Prevalence of sarcopenia and predictors of skeletal muscle mass in healthy, older men and women. J Gerontol A Biol Sci Med Sci 57, M772-M777.

11. Rizzoli R, Reginster JY, Arnal JF, et al. (2013) Quality of life in sarcopenia and frailty. Calcif Tissue Int 93, 101-120.

12. Trombetti A, Reid KF, Hars M, et al. (2016) Age-associated declines in muscle mass, strength, power, and physical performance: impact on fear of falling and quality of life. Osteoporos Int 27, 463-471.

13. Rizzoli R, Stevenson JC, Bauer JM, et al. (2014) The role of dietary protein and vitamin $\mathrm{D}$ in maintaining musculoskeletal health in postmenopausal women: a consensus statement from the European Society for Clinical and Economic Aspects of Osteoporosis and Osteoarthritis (ESCEO). Maturitas 79, 122-132.

14. Bauer J, Biolo G, Cederholm T, et al. (2013) Evidence-based recommendations for optimal dietary protein intake in older people: a position paper from the PROT-AGE Study Group. J Am Med Dir Assoc 14, 542-559.

15. Deutz NE, Bauer JM, Barazzoni R, et al. (2014) Protein intake and exercise for optimal muscle function with aging: recommendations from the ESPEN Expert Group. Clin Nutr 33, 929-936.

16. Cermak NM, Res PT, de Groot LCPGM, et al. (2012) Protein supplementation augments the adaptive response of skeletal muscle to resistance-type exercise training: a meta-analysis. Am J Clin Nutr 96, 1454-1464.

17. Brazier JE, Harper R, Jones NM, et al. (1992) Validating the SF-36 health survey questionnaire: new outcome measure for primary care. BMJ 305, 160-164.

18. Ware JE, Snow KK, Kosinski M, et al. (1993) SF-36 Health Survey Manual and Interpretation Guide. Boston, MA: The Health Institute, New England Medical Center.

19. Henwood TR, Riek S \& Taaffe DR (2008) Strength versus muscle power-specific resistance training in communitydwelling older adults. J Gerontol A Biol Sci Med Sci 63 , 83-91.

20. Liu-Ambrose TY, Khan KM, Eng JJ, et al. (2005) Both resistance and agility training reduce back pain and improve health-related quality of life in older women with low bone mass. Osteoporos Int 16, 1321-1329.

21. Canuto Wanderley FA, Oliveira NL, Marques E, et al. (2015) Aerobic versus resistance training effects on health-related quality of life, body composition, and function of older adults. J Appl Gerontol 34, NP143-NP165.

22. Geirsdottir OG, Arnarson A, Briem K, et al. (2012) Physical function predicts improvement in quality of life in elderly Icelanders after 12 weeks of resistance exercise. J Nutr Health Aging 16, 62-66.

23. Rondanelli M, Opizzi A, Antoniello N, et al. (2011) Effect of essential amino acid supplementation on quality of life, amino acid profile and strength in institutionalized elderly patients. Clin Nutr 30, 571-577. 
24. Payette H, Boutier V, Coulombe C, et al. (2002) Benefits of nutritional supplementation in free-living, frail, undernourished elderly people: a prospective randomized community trial. J Am Diet Assoc 102, 1088-1095.

25. Tieland M, Dirks ML, van der Zwaluw N, et al. (2012) Protein supplementation increases muscle mass gain during prolonged resistance-type exercise training in frail elderly people: a randomized, double-blind, placebo-controlled trial. J Am Med Dir Assoc 13, 713-719.

26. Rondanelli M, Klersy C, Terracol G, et al. (2016) Whey protein, amino acids, and vitamin D supplementation with physical activity increases fat-free mass and strength, functionality, and quality of life and decreases inflammation in sarcopenic elderly. Am J Clin Nutr 103, 830-840.

27. Daly RM, O'Connell SL, Mundell NL, et al. (2014) Proteinenriched diet, with the use of lean red meat, combined with progressive resistance training enhances lean tissue mass and muscle strength and reduces circulating IL-6 concentrations in elderly women: a cluster randomized controlled trial. Am J Clin Nutr 99, 899-910.

28. Australian Bureau of Statistics (1995) National Health Survey. SF-36 Population Norms. Canberra: Commonwealth of Australia.

29. Ware JE \& Kosinski M (2001) Physical \& Mental Health Summary Scales: a Manual for Users of Version 1, 2nd ed. Lincoln, RI: QualityMetric.

30. Ware JE Jr \& Sherbourne CD (1992) The MOS 36-item shortform health survey (SF-36). I. Conceptual framework and item selection. Med Care 30, 473-483.

31. McHorney CA, Ware JE Jr, Rogers W, et al. (1992) The validity and relative precision of MOS short- and longform health status scales and Dartmouth COOP charts. Results from the Medical Outcomes Study. Med Care 30, MS253-MS265.

32. Stewart AL, Mills KM, King AC, et al. (2001) CHAMPS physical activity questionnaire for older adults: outcomes for interventions. Med Sci Sports Exerc 33, 1126-1141.

33. Hoenig JM \& Heisey DM (2001) The abuse of power: the pervasive fallacy of power calculations for data analysis. Am Stat 55, 19-24.

34. Department of Health and Ageing \& National Health and Medical Research Council (2006) Nutrient Reference Values for Australia and New Zealand. Including Recommended Dietary Intakes. Canberra: Commonwealth of Australia.

35. Abizanda P, López MD, García VP, et al. (2015) Effects of an oral nutritional supplementation plus physical exercise intervention on the physical function, nutritional status, and quality of life in frail institutionalized older adults: the ACTIVNES Study. J Am Med Dir Assoc 16, 439.e439-439.e416.

36. Verreijen AM, Verlaan S, Engberink MF, et al. (2015) A high whey protein-, leucine-, and vitamin D-enriched supplement preserves muscle mass during intentional weight loss in obese older adults: a double-blind randomized controlled trial. Am J Clin Nutr 101, 279-286.
37. Breen L \& Phillips SM (2011) Skeletal muscle protein metabolism in the elderly: interventions to counteract the 'anabolic resistance' of ageing. Nutr Metab (Lond) 8, 68.

38. Levinger I, Goodman C, Hare DL, et al. (2007) The effect of resistance training on functional capacity and quality of life in individuals with high and low numbers of metabolic risk factors. Diabetes Care 30, 2205-2210.

39. Alonso J, Ferrer M, Gandek B, et al. (2004) Health-related quality of life associated with chronic conditions in eight countries: results from the International Quality of Life Assessment (IQOLA) Project. Qual Life Res 13, 283-298.

40. Hawthorne G, Osborne RH, Taylor A, et al. (2007) The SF36 Version 2: critical analyses of population weights, scoring algorithms and population norms. Qual Life Res 16, 661-673

41. Inaba Y, Obuchi S, Arai T, et al. (2008) The long-term effects of progressive resistance training on health-related quality in older adults. J Physiol Anthropol 27, 57-61.

42. de Vreede PL, van Meeteren NL, Samson MM, et al. (2007) The effect of functional tasks exercise and resistance exercise on health-related quality of life and physical activity. A randomised controlled trial. Gerontology 53, 12-20.

43. Krist L, Dimeo F \& Keil T (2013) Can progressive resistance training twice a week improve mobility, muscle strength, and quality of life in very elderly nursing-home residents with impaired mobility? A pilot study. Clin Interv Aging 8, 443-448.

44. Sillanpää E, Häkkinen K, Holviala J, et al. (2012) Combined strength and endurance training improves health-related quality of life in healthy middle-aged and older adults. Int J Sports Med 33, 981-986.

45. Beaudart C, Reginster JY, Slomian J, et al. (2015) Estimation of sarcopenia prevalence using various assessment tools. Exp Gerontol 61, 31-37.

46. Samuel D, Rowe P, Hood V, et al. (2012) The relationships between muscle strength, biomechanical functional moments and health-related quality of life in non-elite older adults. Age Ageing 41, 224-230.

47. Napoli N, Shah K, Waters DL, et al. (2014) Effect of weight loss, exercise, or both on cognition and quality of life in obese older adults. Am J Clin Nutr 100, 189-198.

48. Canuto Wanderley FA, Oliveira NL, Marques E, et al. (2015) Aerobic versus resistance training effects on health-related quality of life, body composition, and function of older adults. J Appl Gerontol 34, NP143-NP165.

49. Teixeira LEPP, Silva KNG, Imoto AM, et al. (2010) Progressive load training for the quadriceps muscle associated with proprioception exercises for the prevention of falls in postmenopausal women with osteoporosis: a randomized controlled trial. Osteoporos Int 21, 589-596.

50. Kronhed A, Hallberg I, Odkvist L, et al. (2009) Effect of training on health-related quality of life, pain and falls in osteoporotic women. Adv Physiother 11, 154-165. 